\title{
LOW TRITIUM PARTIAL PRESSURE PERMEATION SYSTEM FOR MASS TRANSPORT MEASUREMENT IN LEAD LITHIUM EUTECTIC
}

\author{
R.J. Pawelko ${ }^{\mathrm{a}, *}$, M. Shimada ${ }^{\mathrm{a}}$, K. Katayama ${ }^{\mathrm{b}}$, S. Fukada ${ }^{\mathrm{b}}$, P.W. Humrickhouse ${ }^{\mathrm{a}}$, and T. Terai ${ }^{\mathrm{c}}$ \\ ${ }^{a}$ Idaho National Laboratory, P.O. Box 1625, Idaho Falls, ID 83415, USA \\ ${ }^{b}$ Kyushu University, Higashi-ku, Fukuoka, 812-8581, Japan \\ ${ }^{c}$ The University of Tokyo, Bunkyo-ku, Tokyo 113-0032, Japan
}

*Corresponding author. Tel. +1-208-533-4792; E-mail address: robert.pawelko@inl.gov

\begin{abstract}
This paper describes a new experimental system designed to investigate tritium mass transfer properties in materials important to fusion technology. Experimental activities were carried out at the Safety and Tritium Applied Research (STAR) facility located at the Idaho National Laboratory (INL). The tritium permeation measurement system was developed as part of the Japan/US TITAN collaboration to investigate tritium mass transfer properties in liquid lead lithium eutectic (LLE) alloy. The experimental system is configured to measure tritium mass transfer properties at low tritium partial pressures. Initial tritium permeation scoping tests were conducted on a $1 \mathrm{~mm}$ thick $\alpha$-Fe plate to determine operating parameters and to validate the experimental technique. A second series of permeation tests was then conducted with the $\alpha$-Fe plate covered with an approximately $8.5 \mathrm{~mm}$ layer of liquid lead lithium eutectic alloy ( $\alpha$-Fe/LLE). We present preliminary tritium permeation data for $\alpha-\mathrm{Fe}$ and $\alpha$-Fe/LLE at temperatures between 400 and $600^{\circ} \mathrm{C}$ and at tritium partial pressures between $1.7 \mathrm{E}-3$ and $2.5 \mathrm{~Pa}$ in helium. Preliminary results for the $\alpha$-Fe plate and $\alpha$-Fe/LLE indicate that the data spans a transition region between the diffusion-limited regime and the surface-limited regime. Additional data is required to determine the existence and range of a surface-limited regime.
\end{abstract}

Keywords: Tritium, Permeation, Lead lithium eutectic, mass transfer properties Abbreviations: LLE (Lead lithium eutectic)

\section{Highlights}

- New low tritium partial pressure permeation system for mass transfer measurements.

- Replaceable permeation cell for studies on metal, molten metal, and salt samples.

- LLE composition: 85.04 mole\% Pb and 14.90 mole\% Li with traces of Bi, Sn, and Zn.

- Tritium permeation has been measured in $\alpha-F e$ and liquid lead lithium eutectic.

- Permeation data spans transition between diffusion and surface limited regimes.

\section{Introduction}

Fusion power promises to provide electricity generation with outstanding safety and environmental performance. Safety plays a crucial role in fusion material selection since tritium behavior in materials determines two key safety evaluation source terms: in-vessel inventory source term and ex-vessel release term, which are used in reactor safety assessments for licensing fusion facilities. Tritium permeation through materials at elevated temperature during long pulse operation is a significant safety concern, and better understanding of tritium behavior in blanket materials is required to build an effective and safe blanket system. Liquid lead lithium eutectic (LLE) alloy has been selected for the heliumcooled lead lithium (HCLL) Test Blanket Module (TBM) in ITER and the dual coolant lead lithium (DCLL) concept, which is the leading blanket system in the US
Fusion Nuclear Science Facility and in future fusion demonstration (DEMO) reactor designs. The tritium partial pressure in these blanket systems is expected to be less than $100 \mathrm{~Pa}$, but there is no experimental database for LLE at low tritium partial pressures.

One task of the Japan/US TITAN collaboration focused on investigating the tritium mass transport properties (permeability, diffusivity, and solubility) in liquid LLE at low tritium partial pressures. To accomplish this task a new tritium permeation measurement system was developed at the Safety and Tritium Applied Research (STAR) facility located at the Idaho National Laboratory (INL). The system is similar to a hydrogen/deuterium permeation measurement system developed at Kyushu University and also incorporates lessons learned from previous tritium permeation experiments conducted at the STAR facility [1]. The Kyushu University hydrogen/deuterium permeation 


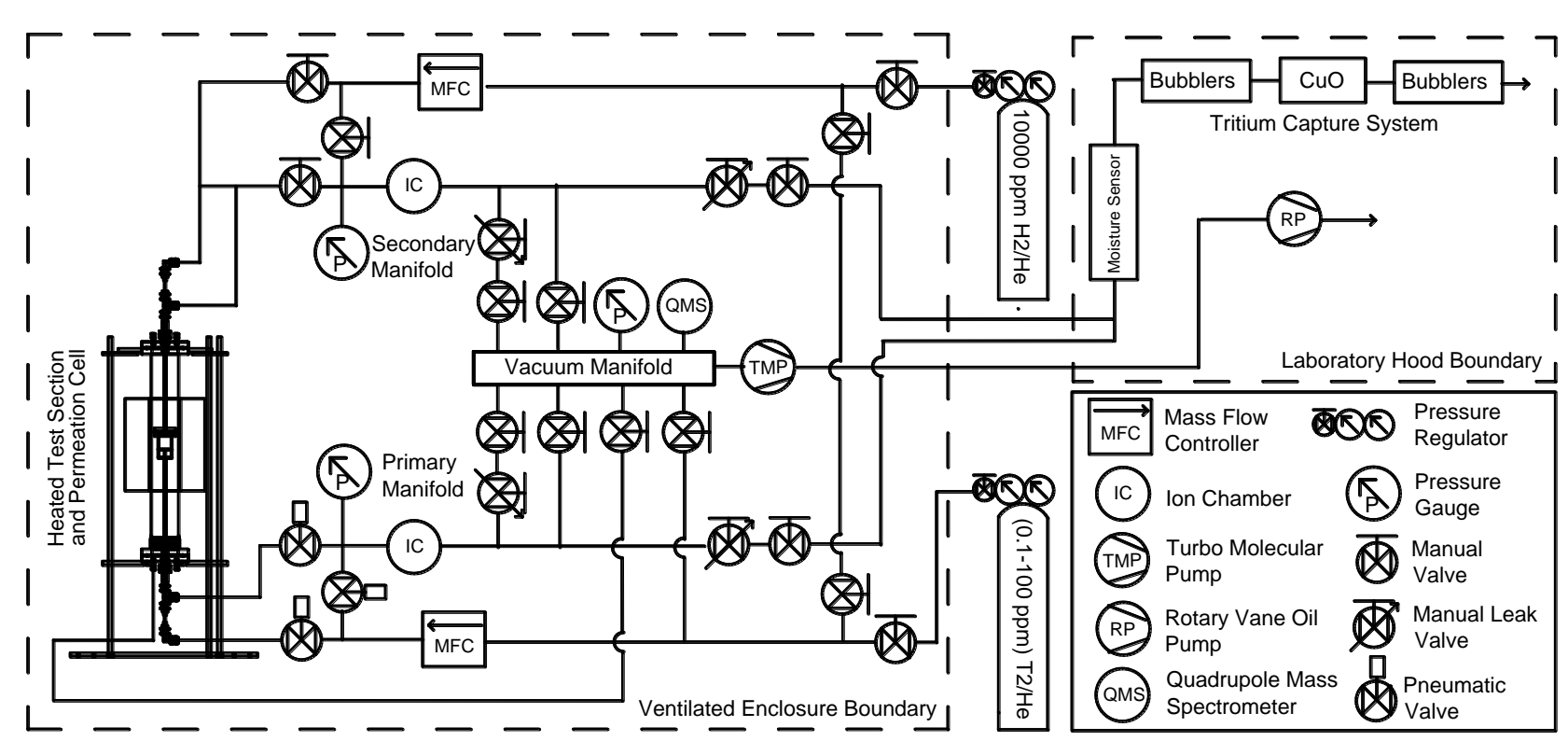

Fig. 1. Simplified schematic of the tritium permeation measurement system.

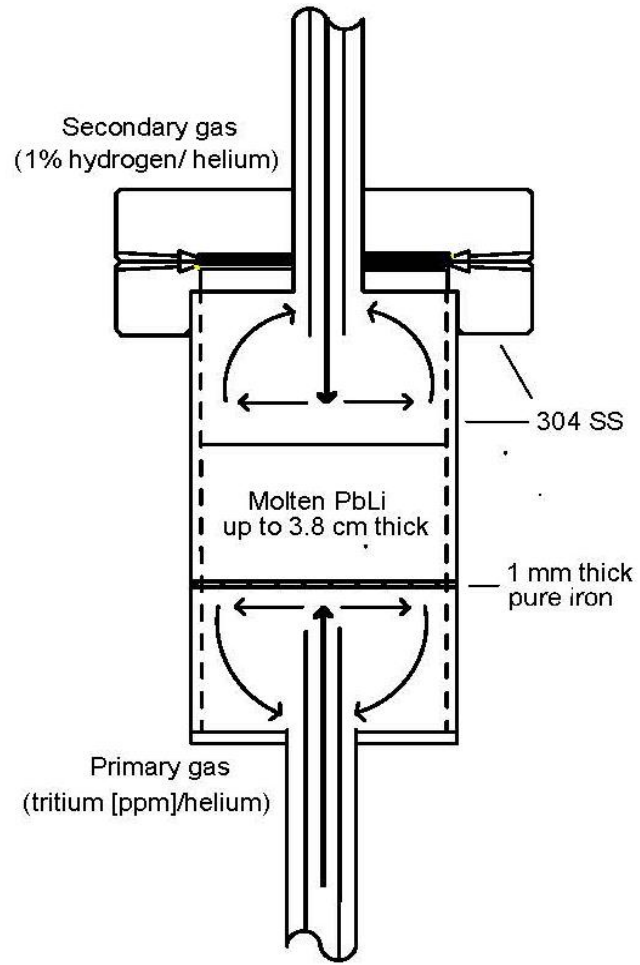

Fig. 2. Diagram of LLE permeation cell.

system was used to obtain the diffusion limited mass transport properties of hydrogen and deuterium in LLE at partial pressures ranging from $10^{2}$ to $10^{5} \mathrm{~Pa}[2,3]$. The STAR facility tritium permeation measurement system compliments the Kyushu University system by investigating the mass transport properties of tritium in LLE at low tritium partial pressures where surface-limited permeation is known to occur in metals.

The tritium permeation measurement system, experimental method, and preliminary permeation data for $\alpha-\mathrm{Fe}$ and $\alpha-\mathrm{Fe} / \mathrm{LLE}$ at low tritium partial pressures $(<2.5 \mathrm{~Pa})$ are hereafter presented and discussed

\section{Experimental system}

The tritium permeation measurement system is housed in a ventilated enclosure and laboratory hood. Figure 1 provides a simplified schematic of the experimental system. The primary components of the system include the LLE permeation cell, two independent gas manifolds, a tritium capture system, and a National Instruments (NI) LabVIEW based control and data acquisition system. A brief description of the system's primary components follows.

The LLE permeation cell is shown in Figure 2. The cell is $4.1 \mathrm{~cm}$ in diameter and constructed of 304 stainless steel. A $1 \mathrm{~mm}$ thick $\left(13.0 \mathrm{~cm}^{2}\right) \alpha-F e$ plate separates the cell into two chambers and also forms the permeation interface separating the primary and secondary gas manifolds. An evacuated quartz tube surrounds the permeation cell preventing tritium permeation from the primary to secondary chamber via the permeation cell walls. A tube furnace maintains the permeation cell at uniform temperature ranging between 300 and $600^{\circ} \mathrm{C}$ and adjustable flow cold guns positioned directly above and below the tube furnace minimize the temperature gradient across the permeation cell. For the LLE experiments a 
101.1 gram PbLi sample was melted on the $\alpha$-Fe plate creating a liquid LLE layer with a calculated thickness from $8.2 \mathrm{~mm}$ at $300^{\circ} \mathrm{C}$ to $8.7 \mathrm{~mm}$ at $600^{\circ} \mathrm{C}$ based upon the density measurement and a surface area of $13 \mathrm{~cm}^{2}$ [4]. The permeation cell is replaceable to accommodate tritium permeation studies on metal, molten metal and salt samples.

Tritium test gas mixtures flow through the primary manifold and bottom chamber of the permeation cell. A 0 to $100 \mathrm{sccm}$ mass flow controller, pressure sensor, and a leak valve are used to establish tritium test gas flow rates and pressures. Tritium concentrations in the primary manifold are measured with a $10 \mathrm{cc}$ Tyne ion chamber with a detection range of with $10^{-3}$ to $10^{6} \mathrm{Ci} / \mathrm{m}^{3}$.

A $1 \%$ hydrogen in helium $\left(1 \% \mathrm{H}_{2} / \mathrm{He}\right)$ sweep gas flows through the secondary manifold and top chamber of the permeation cell. A 0 to $200 \mathrm{sccm}$ mass flow controller, pressure sensor, and a leak valve are used to establish the sweep gas flow rates and pressures. Tritium concentrations in the secondary manifold are measured with a $1000 \mathrm{cc}$ Tyne ion chamber with a detection range of $10^{-6}$ to $10^{3} \mathrm{Ci} / \mathrm{m}^{3}$.

The tritium capture system consists of a pair of ethylene glycol filled bubblers for capturing tritiated water (HTO). These are followed by a $\mathrm{CuO}$ catalyst bed at $600^{\circ} \mathrm{C}$ that converts elemental tritium (HT and/or $\mathrm{T}_{2}$ ) into tritiated water (HTO) which is then captured in a second pair of bubblers containing ethylene glycol. Tritiated gas in the primary and secondary manifolds flows through the capture system prior to being vented to the facility exhaust.

NI LabVIEW control and data acquisition software operates the tritium permeation measurement system. The software operates electro-pneumatic valves and mass flow controllers during experiments while continually recording the temperature, flow rate, pressure, and tritium concentration data.

Auxiliary components include: a turbo molecular vacuum pump system, a quadrupole mass spectrometer, molecular sieve beds, and a moisture sensor to monitor $\mathrm{H}_{2} \mathrm{O}$ concentrations in the manifolds.

\section{Tritium test gas mixtures}

The three tritium test gas mixtures are stored in large 49 liter internal volume cylinders that were originally made for the Tritium Migration, Infiltration and Scintillation Test (TMIST) program. At the end of the program the largely depleted cylinders became available and by re-pressurizing the tanks with UHP helium it was possible to create cylinders with low tritium partial pressures. The three large volume cylinders provided a constant tritium concentration gas supply that was used for multiple extended run tests. During each experiment, tritiated helium gas from the cylinders was assayed using the $10 \mathrm{cc}$ Tyne ion chamber in the primary manifold.
Changing tritium background levels and trapped volumes in the primary manifold influence the measured tritium concentrations. For the $\alpha-\mathrm{Fe}$ experiment series average tritium partial pressures of 1.7E-3, 0.15, and 2.5 $\mathrm{Pa}$ were measured. For the $\alpha-F e / L L E$ measurement series the ion chamber data indicated average tritium partial pressures of 2.2E-2, 0.14, and 2.0 Pa.

\section{Lead lithium eutectic sample}

The LLE sample used in these experiments was supplied by Atlantic Metals and Alloys. The composition of the LLE was determined using inductively coupled plasma mass spectroscopy (ICP-MS) and optical emission spectroscopy (ICP-OES) analysis by sample dissolution in nitric acid conducted on batch samples at the INL analytical laboratories. ICP-MS analysis determined the LLE composition to be 85.04 mole\% $\mathrm{Pb}$ and 14.90 mole\% Li. ICP-OES analysis identified trace quantities of $\mathrm{Bi}, \mathrm{Sn}$, and $\mathrm{Zn}$ in the PbLi eutectic sample.

\section{System calibration}

Calibration issues include: ion chamber, sample temperature, gas flow rate, and pressure calibration.

The experimental technique hinges on the use of Tyne ion chambers to accurately measure tritium concentrations in the primary and secondary manifolds. Prior to conducting experiments, the electronic response of the ion chambers was checked using a Tyne model 7500-CKIT-01-4 calibration kit to verify proper operation and to assure accuracy. A cross check of the ion chamber calibration was performed using data collected during a $300^{\circ} \mathrm{C}$ a-Fe permeation experiment. The check compared the total tritium calculated by numerically integrating the ion chamber data with the total tritium collected in the ethylene glycol traps determined using liquid scintillation counting techniques. The percent difference between the total ion chamber activity and the total ethylene glycol trap activity was approximately $8 \%$.

Sample furnace temperatures were verified using four calibrated Type-K thermocouples (TC). Two TC's are attached to the top and two to the bottom of the permeation cell with one of the bottom TC's controlling the tube furnace temperature. Scoping tests indicated permeation cell temperatures within $15^{\circ} \mathrm{C}$ of the sample furnace control value. The tests also demonstrated the cold guns ability to reduce the temperature gradient across the permeation cell to less than $12^{\circ} \mathrm{C}$.

Tritium test gas and $1 \% \mathrm{H}_{2} / \mathrm{He}$ sweep gas flow rates were established using Sierra Instruments mass flow controllers. For a typical experiment, the tritium test gas flow rate was $50 \mathrm{sccm}$ and the $1 \% \mathrm{H}_{2} / \mathrm{He}$ sweep gas flow rate was $200 \mathrm{sccm}$. The calibration of the mass flow controllers was verified using UHP helium and a standard bubble flow measurement technique. Analysis of the 
bubble-tube measurements indicated a $4 \%$ uncertainty associated with the tritium test gas flow rate and a $3 \%$ uncertainty associated with the $1 \% \mathrm{H}_{2} / \mathrm{He}$ sweep gas flow rate.

Pressures in the primary and secondary manifolds were measured using MKS instruments capacitance manometers. The manometers were zeroed and their calibration verified by reference to the local atmospheric pressure. The pressure difference across the $\alpha$-Fe/liquid LLE permeation interface separating the primary and secondary gas manifolds was maintained at less than 6 torr.

\section{Experimental procedure}

Prior to each experiment the permeation cell and manifolds are purged with a $1 \% \mathrm{H}_{2} / \mathrm{He}$ gas mixture and heated to the test temperature to remove oxides and minimize surface effects. When the permeation cell's temperature, the manifold pressures, and the ion chamber background levels stabilize; the experiment begins by replacing the $1 \% \mathrm{H}_{2} / \mathrm{He}$ gas mixture in the primary manifold with the tritium test gas mixture. During experiments the secondary manifold is purged with a $1 \% \mathrm{H}_{2} / \mathrm{He}$ sweep gas to reduce tritium loses and ion chamber background levels by saturating the secondary manifold's surfaces with $\mathrm{H}_{2}$. The experiment concludes when the tritium concentration in the secondary manifold reach steady-state conditions and the $1 \% \mathrm{H}_{2} / \mathrm{He}$ gas mixture is re-introduced into the primary manifold. Table 1 presents a summary of typical operating parameters. Following each experiment the permeation cell and manifolds are again purged with the $1 \% \mathrm{H}_{2} / \mathrm{He}$ gas mixture and baked out at $100^{\circ} \mathrm{C}$ higher than the test temperature to reduce tritium background levels.

Table I. Typical Operating Parameters

\begin{tabular}{|l|c|}
\hline \multicolumn{1}{|c|}{ Parameter } & Value \\
\hline Primary manifold pressure & $99.6 \mathrm{kPa}-101.7 \mathrm{kPa}$ \\
\hline Secondary manifold pressure & $99.5 \mathrm{kPa}-101.7 \mathrm{kPa}$ \\
\hline $\mathrm{T}_{2}$ test gas/sweep gas flow rate & $50 \mathrm{sccm} / 200 \mathrm{sccm}$ \\
\hline Sample test temperatures & $300,400,500$, and $600^{\circ} \mathrm{C}$ \\
\hline$\alpha-$ Fe/LLE thickness (surface area) & $1 \mathrm{~mm} / 8 \mathrm{~mm}\left(13.0 \mathrm{~cm}^{2}\right)$ \\
\hline $10 \mathrm{cc}$ ion chamber detection range & $10^{-3}$ to $10^{6} \mathrm{Ci} / \mathrm{m}^{3}$ \\
\hline 1 liter ion chamber detection range & $10^{-6}$ to $10^{3} \mathrm{Ci} / \mathrm{m}^{3}$ \\
\hline
\end{tabular}

\section{Results and Discussion}

As stated previously, the experimental technique hinges on the use of ion chambers to accurately measure tritium concentrations in the primary and secondary manifolds. Although ion chamber measurements cannot distinguish between $T_{2}$ and $\mathrm{HT}$, an effective tritium partial pressure $\left(\mathrm{P}_{\mathrm{T}}\right)$ and effective tritium permeation flux $\left(\mathbf{J}_{\mathrm{T}}\right)$ can be defined that correspond directly to the detector's measurements.
$P_{T} \equiv P_{T_{2}}+\frac{1}{2} P_{H T}$

$J_{T} \equiv J_{T_{2}}+\frac{1}{2} J_{H T}$

In this report, the ion chamber data is presented as effective tritium partial pressures and fluxes. In addition, at low tritium concentrations, the ion chamber's signal to background ratio is small which disproportionately increases the uncertainty associated with these measurements.

We present preliminary tritium permeation data for $\alpha$ - $\mathrm{Fe}$ at temperatures between 400 and $600^{\circ} \mathrm{C}$ and average effective tritium partial pressures of 1.7E-3, 0.15, and 2.5 $\mathrm{Pa}$ and for $\alpha$-Fe/LLE at temperatures between 400 and $600^{\circ} \mathrm{C}$ and average effective tritium partial pressures of 2.2E-2, 0.14, and 2.0 Pa.

\section{1 a-Fe sample}

Figure 3 presents effective tritium permeation fluxes for a $1 \mathrm{~mm}$ thick a-Fe plate at $600^{\circ} \mathrm{C}$ as a function of time. The temperature gradient across the cell was less than $12^{\circ} \mathrm{C}$. The traces represent effective tritium partial pressures of $2.5 \mathrm{E}-3,0.15$, and $2.4 \mathrm{~Pa}$ in the primary manifold.

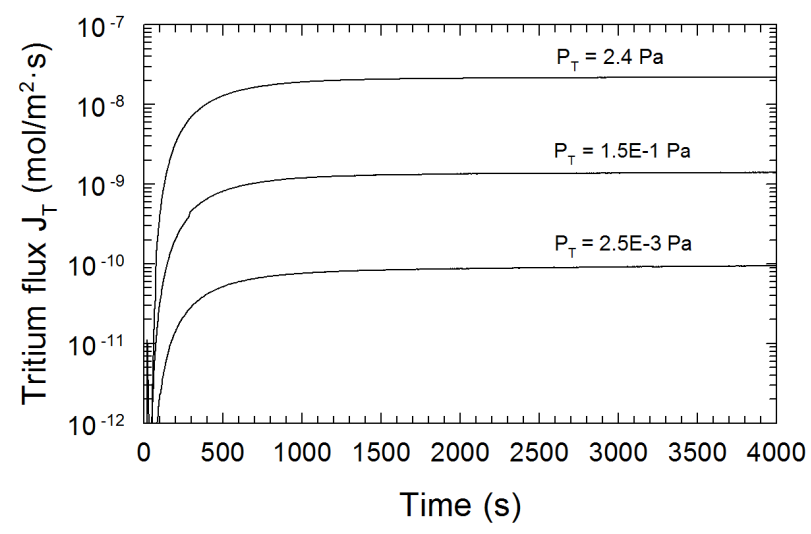

Fig. 3. Tritium permeation fluxes for a-Fe at $600^{\circ} \mathrm{C}$.

Figure 4 displays the steady state a-Fe effective tritium permeation flux values for a series of isotherms as a function of effective tritium partial pressures. 


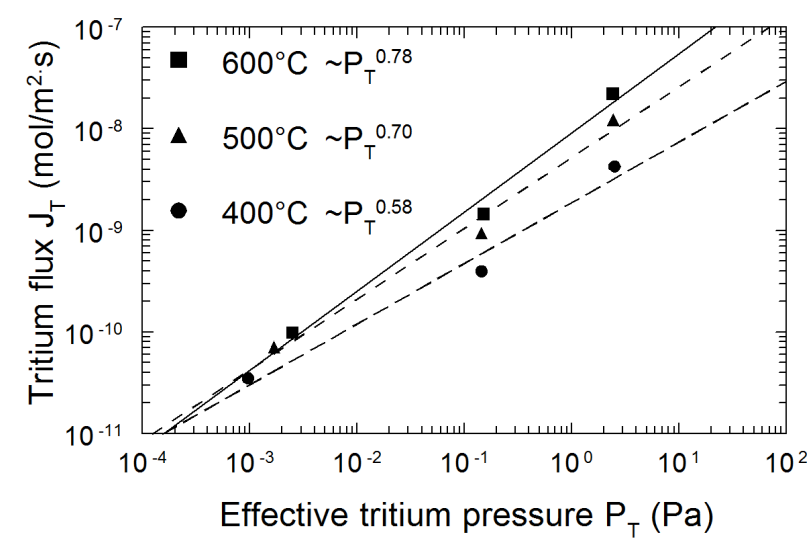

Fig. 4. Steady state tritium permeation flux for a-Fe as a function of tritium partial pressure.

Figure 4 depicts the relationship between the effective tritium permeation flux and the effective tritium partial pressure. It has neither a linear nor a square root dependence on the partial pressure; there are a couple potential explanations for this. A square root dependence on pressure is characteristic of diffusion-limited permeation, which has been observed with hydrogen in LLE at higher partial pressures $\left(10^{2}\right.$ to $\left.10^{5} \mathrm{~Pa}\right)$ [2,3]. A transition to linear dependence is known to occur at lower pressures in metals due to surface-limiting permeation [5]. Similar behavior results when hydrogen is present in far greater quantities than tritium, and the introduced $T_{2}$ is converted almost entirely to HT, in which case the dependence on the HT pressure is linear [6]. Since hydrogen was present in the secondary side of the permeation cell, either of these phenomena may be affecting a transition from diffusion-limited behavior; power-law fits to the data give exponents ranging between 0.78 and 0.58 (note that power-law dependence is not expected in the transition region). With only three data points at each temperature combined with the relatively large uncertainty associated with the very low tritium concentration measurements, additional data is required to determine the existence and range of a surface-limited regime, and to determine the effects of hydrogen.

\section{2. $\alpha$-Fe/liquid LLE sample}

Figure 5 presents tritium permeation fluxes for a $1 \mathrm{~mm}$ thick a-Fe plate covered with an approximately 8.5 $\mathrm{mm}$ thick layer of liquid lead lithium eutectic alloy at $600^{\circ} \mathrm{C}$ as a function of time. A temperature gradient across the cell was measured to be less than $4^{\circ} \mathrm{C}$. The traces represent effective tritium partial pressures of $1.8 \mathrm{E}-2,0.15$, and $2.1 \mathrm{~Pa}$ in the primary manifold.

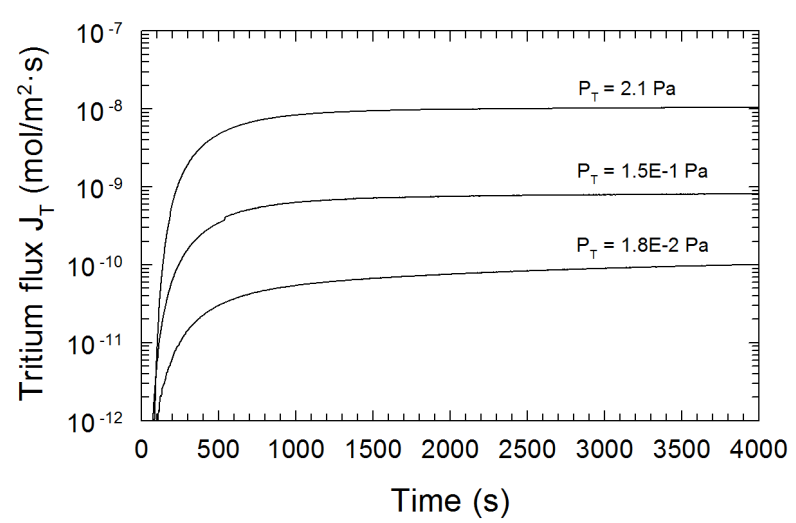

Fig. 5. Titium permeation fluxes for a-Fe/LLE at $600^{\circ} \mathrm{C}$.

Figure 6 displays the steady state a-Fe/LLE effective tritium permeation flux values for a series of isotherms as a function of effective tritium partial pressures. It depicts a relationship between the tritium permeation flux and the tritium partial pressure that is again between linear and square root dependence (power-law fits with exponents ranging between 0.92 and 0.73 are shown for comparison.) As was the case with the $\alpha$-Fe sample, the graph suggests that the a-Fe/LLE data either spans a transition region between the diffusion-limited regime and the surface-limited regime or is influenced by the presence of hydrogen. It is not apparent that the diffusionlimited permeation reported in $\mathrm{H}_{2}$ permeation experiments on $\alpha$-Fe and LLE conducted at significantly higher pressures apply to the current low tritium partial pressure studies [2,3]. Additional data is required to determine the existence and range of a surface-limited regime and isolate the effect of hydrogen addition.

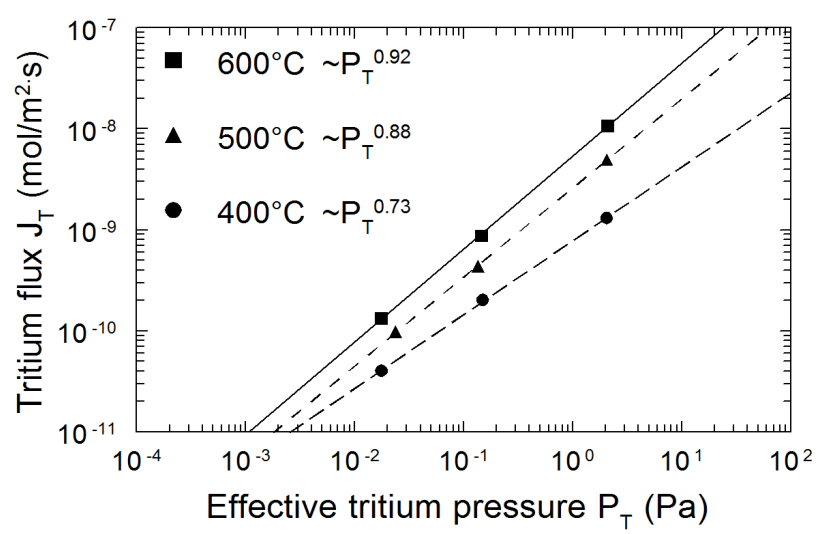

Fig. 6. Steady state tritium permeation flux for a-Fe/LLE as a function of tritium partial pressure.

In Figure 7 tritium permeation fluxes for a-Fe and a-Fe/LLE at $400^{\circ} \mathrm{C}$ are presented as a function of time. The $\alpha$-Fe trace represents tritium permeation through a $1 \mathrm{~mm}$ thick $\alpha$-Fe plate with effective tritium partial pressures of $1.44 \mathrm{E}-1 \mathrm{~Pa}$. The $\alpha-\mathrm{Fe} / \mathrm{LLE}$ trace represents tritium permeation through the $\alpha$-Fe plate and an $8 \mathrm{~mm}$ 
layer of liquid LLE with an effective tritium partial pressure of 1.49E-1 Pa.

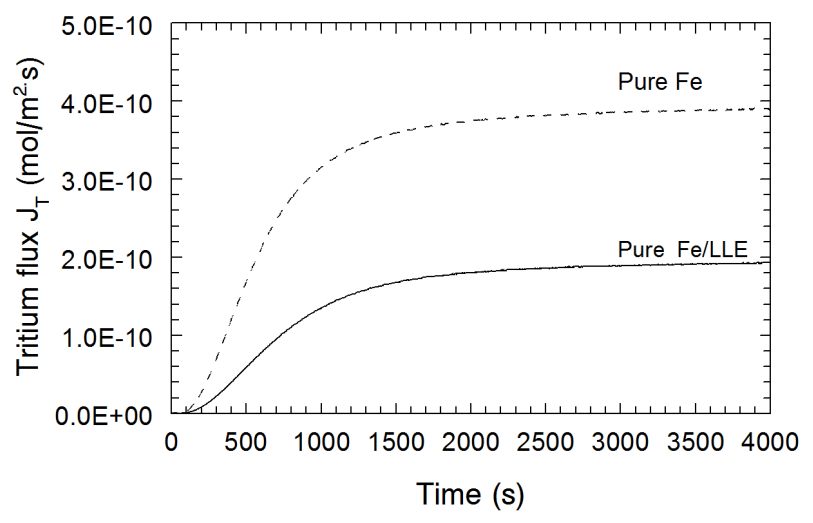

Fig. 7. Tritium permeation curves for a-Fe and a-Fe/LLE at $400^{\circ} \mathrm{C}$.

The data presented in Figure 7 compares the effective tritium permeation fluxes of $\alpha-\mathrm{Fe}$ and $\mathrm{a}-\mathrm{Fe} / \mathrm{LLE}$ at $400^{\circ} \mathrm{C}$ and comparable effective tritium partial pressures. The tritium permeation curves presented in Figure 7 are very different from $\mathrm{H}_{2}$ permeation curves for $\alpha$-Fe and $\alpha-\mathrm{Fe} / \mathrm{LLE}$ that have been reported in literature [2]. In the $\mathrm{H}_{2}$ permeation studies conducted at partial pressures ranging from $10^{2}$ to $10^{5} \mathrm{~Pa}$, the permeation resistance of $\alpha-\mathrm{Fe}$ is two orders of magnitude lower than that of $\alpha-\mathrm{Fe} / \mathrm{LLE}$ and therefore can be considered negligible compared to that of the molten LLE layer. However, in the tritium permeation studies conducted at partial pressures $<2.5 \mathrm{~Pa}$, the steady state permeation flux for $\alpha-\mathrm{Fe}$ is comparable to that of the $\mathrm{a}-\mathrm{Fe} / \mathrm{LLE}$ sample and must be accounted for when determining the permeation flux of tritium in LLE.

Upon completing the $\alpha$-Fe/LLE test series, the permeation cell was opened to visually examine the cell and the LLE layer. Figure 8 shows the solidified LLE layer in the permeation cell following testing. The clean inside cell wall demonstrates the effectiveness of the $1 \% \mathrm{H}_{2} / \mathrm{He}$ sweep gas in removing oxides and minimizing surface effects. The solidified LLE layer has the appearance and texture of a lava flow and is non-uniform in thickness and color. ICP-MS and ICP-OES analysis of core samples are required to characterize the solidified LLE layer following testing. The physical characteristics of the solidified LLE layer formed during cooling and are not representative of the liquid LLE layer. Additional studies are needed to better understand the physical characteristics of the liquid LLE layer.

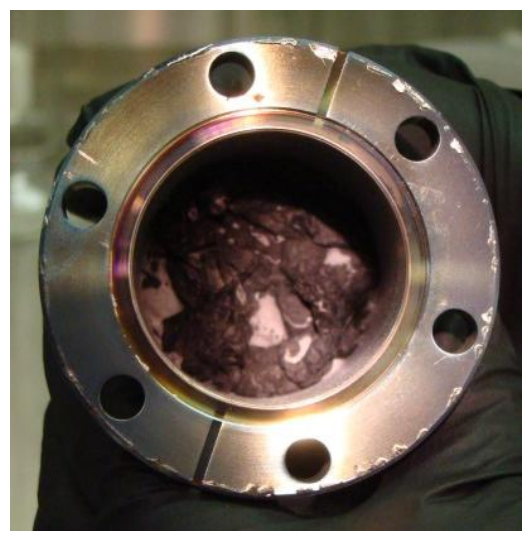

Fig. 8. Solidified LLE layer in the permeation cell. (Color figure)

\section{Conclusions}

In this paper, we have described a system that has been developed to investigate tritium mass transfer properties in materials important to fusion technology at low tritium partial pressures. The system has been used to conduct low tritium partial pressure permeation experiments on $\alpha$-Fe and on $\alpha$-Fe/LLE. Preliminary results have revealed differences between the $\mathrm{H}_{2}$ permeation studies on $\alpha$-Fe and $\alpha$-Fe/LLE reported in literature and the current low tritium partial pressure studies. Diffusion-limited permeation has been reported in $\mathrm{H}_{2}$ permeation experiments on $\alpha-\mathrm{Fe}$ and LLE conducted at partial pressures ranging from $10^{2}$ to $10^{5} \mathrm{~Pa}[2,3]$. The current tritium permeation studies conducted on $\alpha$-Fe and $\alpha-\mathrm{Fe} / \mathrm{LLE}$ at partial pressures less than $2.5 \mathrm{~Pa}$ suggest that the a-Fe/LLE data either spans a transition region between the diffusion-limited regime and the surfacelimited regime, or has been influenced by the addition of hydrogen on the secondary side.

Additional data is required to determine the existence and range of surface-limited tritium permeation in LLE at low tritium partial pressures and to investigate the influence of the $1 \% \mathrm{H}_{2} / \mathrm{He}$ sweep gas on the tritium permeation in LLE at low tritium partial pressures. To obtain this data a new gas supply system is being fabricated to supply various low partial pressure hydrogen isotope gas mixtures to experiments. Gas mixtures considered for preparation include $\leq 100 \mathrm{ppm} \mathrm{T}_{2}$ and $\leq 20000 \mathrm{ppm}_{2}$ with $\mathrm{He}$ as the diluent. This new system provides the hardware to fill gaps in the current database and also to study the effects of hydrogen. The system is scheduled to be operational in the fourth quarter of 2015 . Additional funding is still required to conduct the additional experiments necessary to obtain a better understanding of the tritium mass transfer properties in LLE at low tritium partial pressures. When addition data is obtained, a subsequent publication on the tritium mass transfer properties in LLE that also makes use of Tritium 
Migration Analysis Program (TMAP) models will be issued.

\section{Acknowledgments}

This work was prepared for the U.S. Department of Energy, Office of Fusion Energy Sciences; and conducted within the framework of the Japan/US TITAN collaboration for fusion research.

This manuscript has been authored by Battelle Energy Alliance, LLC under Contract Number. DE-AC07-05ID14517 with the U.S. Department of Energy. The United States Government retains and the publisher, by accepting the article for publication, acknowledges that the United States Government retains a nonexclusive, paid-up, irrevocable, world-wide license to publish or reproduce the published form of this manuscript, or allow others to do so, for United States Government purposes.

\section{References}

[1] P Humrickhouse, R.J. Pawelko, M. Shimada, P. Winston, Tritium Permeability of Incoloy $800 \mathrm{H}$ and Inconel 617, INL/EXT-11-23265 (2012).

[2] Y. Edao, H. Noguchi, S. Fukada, Experiments of Hydrogen Isotope Permeation, Diffusion and Dissolution in Li-Pb, Journal of Nuclear Material 417 (2011)723-726.

[3] H. Okitsu, Y. Edao, M. Okada, S. Fukada, Analysis of Diffusion and Dissolution of TwoComponent Hydrogen (H+D) in Lead Lithium, Fusion Engineering and Design 87 (2012) 1324-1328.

[4] B. Schultz, Thermophysical Properties of Li (17) $\mathrm{Pb}$ (83) Alloy, Fusion Engineering and Design 14 (1991) 199-205.

[5] I. Ali-Khan, K.J. Dietz, F.G. Waelbroeck, P. Wienhold, The rate of hydrogen release out of clean metallic surfaces, Journal of Nuclear Materials 76-77 (1978) 337-343.

[6] J.T. Bell, J.D. Redman, Permeation of Hydrogen Isotopes in Nickel, Journal of Physical Chemistry 82 no. 26 (1978) 2834-2838. 